\title{
Do invisível ao visível para História da educação, Laura Ribeiro Lopes 1953/ 1959
}

\author{
Francine Cerqueira dos Santos; Ione Celeste de Sousa Terceiro Autor ${ }^{3}$ e \\ Quarto Autor ${ }^{4}$ \\ 1. Bolsista PIBIC/CNPq, Graduando em geografia, Universidade Estadual de Feira de Santana, \\ francinecerqueiradossantos@gmail.com \\ 2. Ione Celeste de Sousa, DCHF, Universidade Estadual de Feira de Santana, ionecjs@gmail.com \\ 3. Participante do projeto ou núcleo tal, Departamento de Nome, Universidade Estadual de Feira de \\ Santana, e-mail: codinome@provedor.br \\ 4. Participante do projeto ou núcleo tal, Departamento de Nome, Universidade Estadual de Feira de \\ Santana, e-mail: codinome@provedor.br
}

PALAVRAS-CHAVE: Laura Ribeiro Lopes, Histoóia da Educação no Ensino de geografia, Feira de Santana

\section{INTRODUÇÃO}

O trabalho propôs-se a investigar o livro publicado por Laura Ribeiro Lopes em 1959, A geografia de Feira de Santana, embora a leitura de todas as quatros obras foram lidas de modo a consolidar o conhecimento e facilitar análise dos matérias feitos esta protagonista do ensino da geografia feirense, como sujeito que teve as experiências de normalista, escritora e professora - tendo sido a primeira pesquisadora da geografia feirense a escrever sobre o campo.

Contudo, em que pese o significado local da sua produção não existem estudos sobre ela. Fazê-lo é também uma forma de analisar o papel designado às mulheres de uma forma geral, que incidia inclusive para aquelas que tiveram uma profissão reconhecida socialmente, como o ser professora primária.

Para atingir os objetivos da pesquisa utilizei como fontes históricas textos de jornais de época, blogs atuais e um dos livros escritos por Laura Ribeiro Lopes: Geografia de Feira de Santana (1959),.

'Laura Ribeiro Lopes, nasceu em Feira de Santana em 14 de janeiro de 1913. Filha de João Ribeiro Lopes e Maria Emília Lopes (comerciante e dona de casa) veio de uma família de nove irmãos, sete moças e dois homens (httpp://www.academiadeeducacao.org.br/lauralopes.htm).

A professora Laura Ribeiro Lopes fez parte da primeira turma da ENFsa, diplomada em 1930, turma da Minoria. Segundo SOUSA (1999/2001)e CRUZ(2000) esta instituição, criada em 1927, esteve inserida no processo de modernização urbana de Feira de Santana que teve como um dos seus projetos "a alfabetização do Sertão". Apesar de sua atuação no magistério primário da 
região desde 1930, a pesquisa investiga a trajetória desta professora entre 1953 a 1959, período no qual elaborou a o texto "Geografia de Feira de Santana", monografia ${ }^{1}$ apresentada para promoção de carreira como docente à Escola Normal da Feira de Santana.

As fontes ( registros) iniciais que levantei sobre a professora Laura Ribeiro Lopes foram os Blogs feirenses...Academia da Educação de feira de Santana(www.academiadeeducação)e o site De Olho na Cidade (https://www.deolhonacidade.net/noticias/2141/professores-que-fizeram-ahistória-de-feira-de Santana.html).

Laura Ribeiro Lopes foi à primeira mulher escritora de Feira de Santana. Como Pesquisadora, publicou obras literárias. São seus livros: Conhecimentos Gerais com a Geografia de Salvador (para a $2^{\underline{a}}$ série),1965; Geografia da Bahia (1964); Feira de Santana Estudos Sociais e Ciências Naturais - Curso primário; Feira de Santana Geografia para o curso primário (1959).

https://www.deolhonacidade.net/noticias/2141/professores-que-fizerama-história-de-feira-de Santana.html).

\section{MATERIAL E MÉTODOS OU METODOLOGIA (ou equivalente)}

A base da proposta de pesquisa são as proposições da História Cultural Educação, tendo como fonte os escritos da professora de geografia feirense Laura Ribeiro Lopes. O objetivo principal foi destacar a perspectiva de geografia que embasava seus escritos, cuja proposta inicial constava de 3 títulos:

a) Geografia da Bahia (1964);

b) Feira de Santana: Estudos Sociais e Ciências Naturais- Curso Primário. (1959);

c) Feira de Santana: geografia para o curso primário (1959);

Este objetivo inicial foi mantido mesmo na diminuição para apenas um texto Feira de Santana: geografia para o curso primário- que trata da formação geográfica da cidade, a partir do conteúdo apresentado, centrado na descrição de aspectos voltados para uma geografia social por tratar da organização espacial e dos elementos que compõem o mesmo. Esta forma de escrever e dialogar estava compatível com o sistema de ensino da época por enfatizar a memorização de dados.

Um segundo objetivo foi apreender a autora, Laura Ribeiro Lopes, como participante de uma cultura escolar que enfatizava a inculcação dos conteúdos a partir de práticas pedagógicas como rigor disciplinar, memorização e repetição de atividades

\footnotetext{
${ }^{1}$ Um exemplar da Monografia original existente na Biblioteca Municipal de Fsa foi extraviada em reestruturação desta na gestão de 2006/2008.
} 
Considerei como cultura escolar a proposição de Dominique Julia (2001, p.10) que enfoca as relações entre as práticas escolares dentro e fora do ambiente escolar stritu,

\begin{abstract}
, (...)cultura escolar; tanto isso é verdade que esta cultura escolar (não pode ser estudada sem a análise precisa das relações conflituosas ou pacíficas que ela mantém, a cada período de sua história, com o conjunto das culturas que Ihe são contemporâneas: cultura religiosa, cultura política ou cultura popular. Para ser breve, poder-se-ia descrever a cultura escolar como um conjunto de normas que definem conhecimentos a ensinar e condutas a inculcar, e um conjunto de práticas que permitem a transmissão desses conhecimentos e a incorporação desses comportamentos; normas e práticas coordenadas a finalidades de socialização".
\end{abstract}

Neste período a educação estava voltada como principal razão para 0 processo modernizador e civilizador do país que daria-se pelas escolas pelas Escolas Normais sendo as normalistas sinônimo de conhecimento e status sociais por ajudar no progresso do país.

\title{
MATERIAIS:
}

Livro Geografia de Feira de Santana , 1959 escrito por Laura Ribeiro Lopes Jornais

Fontes Orais

\section{CONSIDERAÇÕES FINAIS (ou Conclusão)}

A pesquisa reafirmou a importância da professora Laura Ribeiro Lopes, para a escrita de uma história da educação em Feira de Santana. Antes desta protagonista não existiam livros didáticos geográficos sistematizados para Feira de Santana, que explicitassem os sujeitos feirense. A contribuição para geografia foi dar ao local visibilidade; deu a geografia construção e ao mesmo tempo reconstrução, como fazer pedagógico.

Considerei que a autora ficou "invisível" até o presente para as pesquisas acadêmicas enquanto pesquisadora. Como mulher na produção do conhecimento rompeu de alguma forma com as demarcações de gênero, conceito de análise que, embora não seja o foco da pesquisa, contribuiu para falta compreensão desta invisibilidade do seu fazer-saber autoral no magistério.

\section{REFERÊNCIAS}

- CARVALHO, Anelise. M. Muller de (1994). Reafirmação e delimitação do papel feminino nos livros didáticos dos anos 30/40. São Paulo, Revista Projeto

- CARVALHO, Marília Pinto de (1994). Mestra sim, tia também: professoras de 1ograu na periferia de São Paulo. Revista Projeto História: mulher e educação

- SOUSA. Ione Celeste. Garotas tricolores: Deusas Fardadas. 2001. Dissertação de mestrado (História Social) Dissertação( História Social)PUC_p. 197-197

- CALLAI, Helena C. Aprendendo a ler o mundo: a geografia nos anos iniciais do ensino fundamental. In Cadernos Cedes N. 66. São Paulo: Cortez, Campinas: Cedes, 2005, p. 227-248. 
- CRUZ, António Roberto Seixas da. Mestres e mestras para o Sertão: criação e funcionamento da Escola Normal de Feira de Santana. FSA: Sitientibus, no 31, jul/ dez 2004.Pp143-168

- FONSECA, Selva G. BORGES, Vilmar J. SILVA JR, Astrogildo F. Ensinar Geografia e História - relações entre sujeitos, saberes e práticas. In FONSECA, Selva G. (org). Currículos, saberes e culturas escolares. Campinas: Ed. Alínea. 2007

- $\quad$ CRUZ, Neide Almeida da ; SILVA, Marília Queiroz da. 50 anos de educação. Feira de Santana-BA: Graficartes, 1977.

- LOURO, Guacira Lopes : Mulheres na Sala de Aula 1997. "In: História das Mulheres no Brasil. São Paulo, Unesp/Contexto.

- BARBOSA, Maria Laura Puglisi: Análise de conteúdo. Brasília , 2012.

- OlIVEIRA, Luciana Amorim. Ensino de Geografia Memória e Representações socias:RAJETÓRIAS DE VIDA DE PROFESSORAS DE GEOGRAFIA GRADUADAS

- LOPES, Laura Ribeiro: Feira de Santana, Geografia para o Curso Primário; 1959 